\title{
Investigation on the toxic interaction of superparamagnetic iron oxide nanoparticles with catalase
}

\author{
Zehua Yu ${ }^{\mathrm{a}, 1}$, Hongwei Liu ${ }^{\mathrm{a}, \mathrm{b}, 1}$, Xinxin $\mathrm{Hu}^{\mathrm{a}}$, Wei Song ${ }^{\mathrm{a}}$, Rutao Liu ${ }^{\mathrm{a}, *}$ \\ a Shandong Key Laboratory of Water Pollution Control and Resource Reuse, School of Environmental Science and Engineering, China-America CRC for \\ Environment \& Health, Shandong Province, Shandong University, 27\# Shanda South Road, Jinan 250100, PR China \\ ${ }^{\mathrm{b}}$ Research Center for Eco-Environmental Sciences, Chinese Academy of Sciences, Beijing 100085, PR China
}

\section{A R T I C L E I N F O}

\section{Article history:}

Received 30 November 2013

Received in revised form

7 October 2014

Accepted 21 October 2014

Available online 29 October 2014

Keywords:

\section{Nanotoxicology}

Superparamagnetic nanometer iron oxide

Catalase

Molecular conformation

Function

\begin{abstract}
A B S T R A C T
Superparamagnetic iron oxide nanoparticles (SPIONs) have been investigated for various applications in targeted drug delivery and magnetic resonance imaging. Given their clinical relevance, there is a need to understand these particles' potential cytotoxic effects and possible mechanisms of cytotoxicity. Using a variety of spectroscopic techniques, we investigated the interaction of SPIONs with catalase (CAT) in an aqueous environment. Catalase is an important enzyme that protects cells and tissues from oxidative damage by reactive oxygen species (ROS). Therefore, in this work, CAT served as a model protein for examining the physiological effects of SPIONs due to is function in eliminating $\mathrm{H}_{2} \mathrm{O}_{2}$. Synchronous fluorescence spectroscopy results showed that SPIONs have little effect on tryptophan residues in CAT. Data from circular dichroism (CD) and UV-vis spectroscopies showed that CAT $\alpha$-helical content decreased from $32.4 \%$ to $29.1 \%$ in the presence of SPIONs. Moreover, a ca. $10 \%$ decrease in CAT activity was observed in the presence of SPIONs at a 20:1 particle:protein ratio. These results show that SPIONs can interact with proteins to alter both their structure and function. Further studies with CAT or other toxicologically relevant enzymes may be used for elucidating the mechanisms of SPION cytotoxicity.
\end{abstract}

(C) 2014 Elsevier B.V. All rights reserved.

\section{Introduction}

Nanotoxicology, as a new area of research, is becoming a new research hotspot gradually. Recently, particular attention has been devoted to study in toxicology of nanoparticles [1]. Due to its unique physical and chemical properties, superparamagnetic iron oxide nanoparticles (SPIONs) has shown prospect in vivo applications such as magnetic resonance imaging, tissue repair, immunoassay, hyperthermia, drug delivery, cell separation, etc. [2-4].

As a targeted drug deliverer for clinical medicine research, the surface engineered SPIONs (i.e. with targeting ligand attached to their surfaces) can be guided to the specified site where the drug is released locally through an external magnetic field. Its magnetic properties depend strongly on the size of the magnetic particles and it offers guidance for applying proper diagnostics modalities to treat diseases in the field of medicine [5-7].

Despite an increasing interest in studying the cytotoxicity of SPIONs [8-11], little work has been carried out which focuses on investigating the interaction mechanism between the SPIONs and

\footnotetext{
* Corresponding author. Tel./fax: + 8653188364868.

E-mail address: rutaoliu@sdu.edu.cn (R. Liu).

1 These authors contributed equally to this work and share the first author.
}

protein at the molecular level. Here, we prepared $\mathrm{Fe}_{3} \mathrm{O}_{4}$ nanoparticles by co-precipitation of $\mathrm{Fe}^{3+}$ and $\mathrm{Fe}^{2+}$ in alkaline medium under nitrogen atmosphere [12-14]. And catalase $\left(\mathrm{H}_{2} \mathrm{O}_{2}: \mathrm{H}_{2} \mathrm{O}_{2}\right.$ oxidoreductase, EC 1.11.1.6; CAT) is selected as our model functional protein owing to its importance in protecting the cells and tissues from oxidative damage by reactive oxygen species (ROS) [15-19].

In our research, multi-spectroscopic techniques including fluorescence, synchronous fluorescence, UV-vis absorption and circular dichroism were used to investigate the conformation changes for SPIONs binding to CAT. Besides, experiments of CAT inactivation and reactivation under simulative physiological condition were also studied. This study is a reference for further elaborating the adverse impact on CAT induced by SPIONs and is helpful for seeking a clinical control or detoxification methods.

\section{Materials and methods}

\subsection{Reagents}

Catalase (CAT, Sigma) was purchased from Shanghai Trading Co., Ltd. $\mathrm{H}_{2} \mathrm{O}_{2}$ (30\%) was purchased from Beijing Sinopharm Chemical Reagent Co., Ltd. (Beijing, China). CAT was dissolved in 
ultrapure water to form a $1 \times 10^{-5} \mathrm{~mol} / \mathrm{L}$ solution for later use. $\mathrm{FeCl}_{3} \cdot 6 \mathrm{H}_{2} \mathrm{O}, \mathrm{FeCl}_{2} \cdot 4 \mathrm{H}_{2} \mathrm{O}, 25 \%$ aqueous ammonia, citric acid, and nitrogen were used for the synthesis of SPIONs, whose stock solution $(1.8 \mathrm{mg} / \mathrm{L})$ was prepared by peptizing the synthetic particles in a $500 \mathrm{ml}$ volumetric flask. A $0.2 \mathrm{~mol} / \mathrm{L}$ mixture of phosphate buffer (mixture of $\mathrm{NaH}_{2} \mathrm{PO}_{4} \cdot 2 \mathrm{H}_{2} \mathrm{O}$ and $\mathrm{Na}_{2} \mathrm{H}-$ $\mathrm{PO}_{4} \cdot 12 \mathrm{H}_{2} \mathrm{O}, \mathrm{pH}=7.4$ ) was used to control the $\mathrm{pH} . \mathrm{H}_{2} \mathrm{O}_{2}$ was dissolved in ultrapure water and diluted to $0.03 \%$ solution.

All the solutions were stored at $0-4{ }^{\circ} \mathrm{C}$ and ultrapure water (18.25 M $\Omega$ ) was used throughout the experiments. And all other reagents were of analytical grade.

\subsection{Probing the interaction of SPIONs with CAT}

\subsubsection{Fluorescence and synchronous fluorescence measurements}

Fluorescence measurements were carried out with a $1 \mathrm{~cm} \times 1 \mathrm{~cm}$ quartz cell, using excitation and emission slit widths of $5 \mathrm{~nm}$. Fluorescence spectra were recorded at two different temperatures ( $293 \mathrm{~K}$ and $310 \mathrm{~K}$ ) on a HITACHI FL-4600 fluorescence spectrophotometer (Hitachi, Japan). The systems were excited at $278 \mathrm{~nm}$, and emission wavelength was recorded from $290 \mathrm{~nm}$ to $430 \mathrm{~nm}$ at the scanning speed of $1200 \mathrm{~nm} / \mathrm{min}$ and the PMT (Photo-Multiplier Tube) voltage of $600 \mathrm{~V}$.

The synchronous fluorescence spectra were measured at $\lambda_{e x}=250 \mathrm{~nm}, \Delta \lambda=15 \mathrm{~nm}$ and $\Delta \lambda=60 \mathrm{~nm}$. All the test requirements were the same as more of fluorescence measurements.

\subsubsection{UV-visible absorption measurements}

UV-visible spectra were collected in the range of 190-350 nm. A gradually increased volume of SPIONs solutions and a fixed amount of CAT were added to volumetric flasks in sequence, and then diluted with ultrapure water to $10 \mathrm{~mL}$. The equilibrated solution was poured into $1 \mathrm{~cm}$ quartz cells and measured on a SHIMADZU UV-2450 spectrophotometer (Shimadzu, Japan) using SPIONs solutions mixed with buffer as references.

\subsubsection{Circular dichroism (CD) measurements}

$\mathrm{CD}$ spectra measurements were performed over the range of $200-250 \mathrm{~nm}$ in $0.5 \mathrm{~nm}$ intervals on a J-810 Spectropolarimeter (Jasco, Japan). The scanning rate was adjusted to $200 \mathrm{~nm} / \mathrm{min}$. The spectra were measured in a temperature-controlled $1 \mathrm{~cm}$ path length cell.

\subsubsection{Catalase activity measurements}

We defined one unit of CAT activity as the amount of enzyme that decomposes $1 \mathrm{mmol} \mathrm{H}_{2} \mathrm{O}_{2}$ per minute. The enzymatic activity was measured spectrophotometrically by detecting the decrease in hydrogen peroxide absorption at $240 \mathrm{~nm}$ in a $20 \mathrm{mM}$ buffer phosphate medium ( $\mathrm{pH} 7.4)$ [20,21]. The reaction was initiated by the addition of CAT. The inhibition rate of CAT activity was calculated by the following equation:

inhibition rate $=\frac{\Delta A_{\chi}}{\Delta A_{0}} \times 100 \%$

where $\Delta A_{x}$ and $\Delta A_{0}$ are the reduction of the absorption value at $240 \mathrm{~nm}$ of the hydrogen peroxide solution in 30,60 and $90 \mathrm{~min}$ after the addition of CAT with and without SPIONs, respectively.

\section{Results and discussion}

\subsection{Research on quenching mechanism}

Fluorescence spectroscopy has been the most popular method to investigate the interaction of proteins and ligands. This

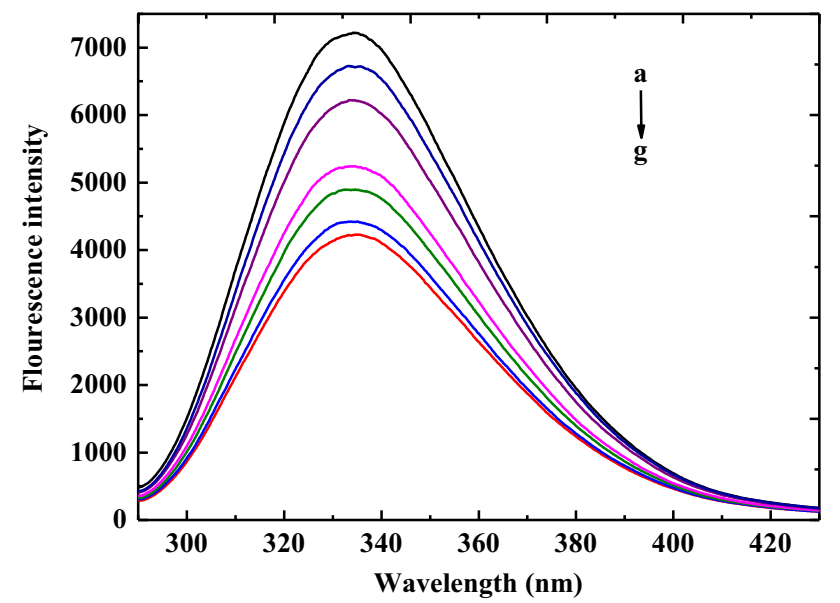

Fig. 1. Fluorescence emission spectra of CAT with different concentration of SPIONs. Conditions: $C$ (CAT) $1.0 \times 10^{-6} \mathrm{~mol} / \mathrm{L}$; SPIONs (a)-(g) $0 ; 2.5 ; 5.0 ; 7.5$; $10.0 ; 12.5 ; 15\left(\times 10^{-6} \mathrm{~mol} / \mathrm{L}\right) ; \mathrm{PBS} 2.0 \times 10^{-2} \mathrm{~mol} / \mathrm{L}(\mathrm{pH}=7.40) ; T=293 \mathrm{~K}$.

technology can provide us with all the information about the quenching mechanism, including binding constants and binding sites.

The inner filter effect (IFE) caused by absorption of the excitation and/or emission radiation is often neglected in many studies. For eliminating IFE, we imported the IFE correction equation (1) and obtained a plot (Fig. 1) of fluorescence quenching with increasing concentration of SPIONs corrected for IFE [22]:

$F_{c o r}=F_{o b s} \times 10^{\left(A_{e x}+A_{e m}\right) / 2}$

where $F_{c o r}$ is the corrected fluorescence intensity,and $F_{o b s}$ is the observed fluorescence intensity; $A_{e x}$ and $A_{e m}$ are the sum of the absorbance of protein and ligand at the excitation and emission wavelengths of the fluorescence measurements, respectively.

For a small molecule can quench the intrinsic fluorescence of proteins, the aromatic amino acid residues must be located in or near the binding site. The fluorescence intensity of CAT decreases regularly with an increasing concentration of SPIONs, which indicates the strong interaction between SPIONs and CAT [23].

Quenching mechanisms are classified as static and dynamic quenching, where dynamic quenching results from collision between the quencher and protein. A higher temperature results in larger diffusion coefficients, so the quenching constants will increase with raising temperature. In contrast, increased temperature is likely to result in decreased stability of the complexes and thus lower the value of the static quenching constants [24]. To verify this, the fluorescence quenching data were analyzed according to the Stern-Volmer equation [25]

$F_{0} / F=1+K_{s v}[Q]=1+k_{q} \tau_{0}[Q]$

where $F_{0}$ and $F$ are the fluorescence intensities in the absence and presence of the quencher, respectively. $K_{S V}$ is the Stern-Volmer quenching constant and $[Q]$ is the concentration of the quencher; $k_{q}$ is the quenching rate constant of the biological macromolecule and the maximum dynamic quenching constant of various quenchers is $2.0 \times 10^{10} \mathrm{~mol} / \mathrm{l} / \mathrm{s}[26] ; \tau_{0}$ is the fluorescence lifetime without quencher. The Stern-Volmer plots for the quenching of CAT by SPIONs at two different temperatures are shown in Fig. 2.

$K_{S V}$ and $k_{q}$ at two different temperatures are listed in Table 1. The results indicated that the values of quenching constants decreased with increasing temperature and the values of $k_{q}$ were much greater than $2.0 \times 10^{10} \mathrm{~mol} / \mathrm{l} / \mathrm{s}$. This analysis implied that the fluorescence quenching was attributed to static quenching.

For the static quenching, results from fluorescence measurements can be employed to estimate the binding constants of the 


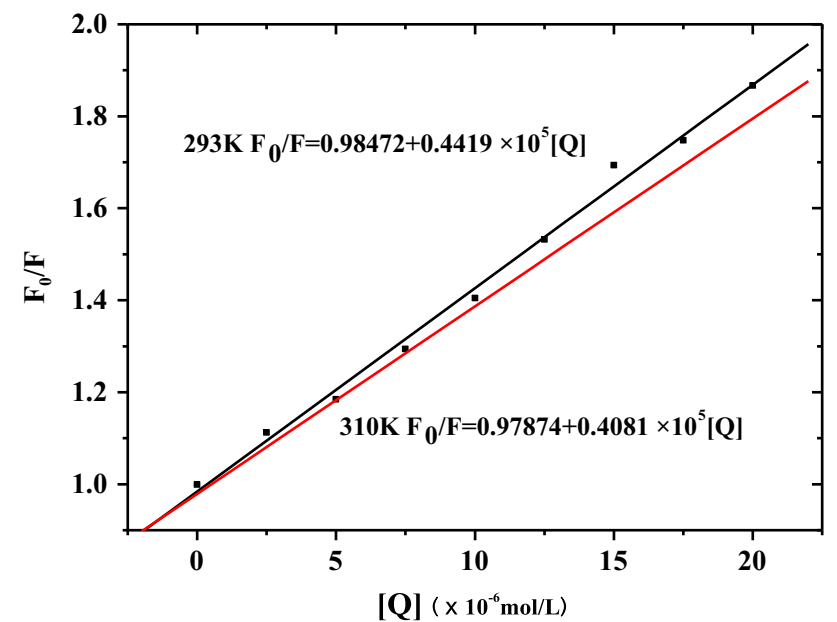

Fig. 2. Stern-Volmer plots for the quenching of CAT by SPIONs at $293 \mathrm{~K}$ and $310 \mathrm{~K}$. Conditions: $C$ (CAT) $1.0 \times 10^{-6} \mathrm{~mol} / \mathrm{L}$; SPIONs (a)-(g) $0 ; 2.5 ; 5.0 ; 7.5 ; 10.0 ; 12.5$; $15\left(\times 10^{-6} \mathrm{~mol} / \mathrm{L}\right) ;$ PBS $2.0 \times 10^{-2} \mathrm{~mol} / \mathrm{L}(\mathrm{pH}=7.40)$.

Table 1

The Stern-Volmer quenching constants for the interaction of SPIONs with CAT at $293 \mathrm{~K}$ and $310 \mathrm{~K}$.

\begin{tabular}{llllll}
\hline $\mathrm{pH}$ & $T(\mathrm{~K})$ & $K_{s v}\left(\times 10^{5} \mathrm{~L} / \mathrm{mol}\right)$ & $k_{q}\left(\times 10^{12} \mathrm{~L} / \mathrm{mol} \mathrm{s}\right)$ & $R^{\mathrm{a}}$ & S.D. $^{\mathrm{b}}$ \\
\hline 7.4 & 293 & 0.4419 & 4.419 & 0.9943 & 0.0244 \\
7.4 & 310 & 0.4081 & 4.081 & 0.9915 & 0.0276 \\
\hline
\end{tabular}

Table 2

Binding constants and relative thermodynamic parameters of the SPIONs-CAT system.

\begin{tabular}{llll}
\hline$T(\mathrm{~K})$ & $K_{A}\left(\times 10^{4} \mathrm{~L} / \mathrm{mol}\right)$ & $n$ & $R^{a}$ \\
293 & 5.46 & 1.02 & 0.9901 \\
\hline
\end{tabular}

${ }^{\mathrm{a}} \mathrm{R}$ is the correlation coefficient for the $K_{A}$ values.

CAT-SPIONs by a different form of the Stern-Volmer equation:

$\log \left(\frac{F_{0}-F}{F}\right)=\log K_{A}+n \log [Q]$

where $F_{0}, F$ and $[Q]$ are the same as in Eq. (3), $n$ is the number of average binding sites, and $K_{A}$ is the binding constant. The values of $n$ and $K_{A}$ at $293 \mathrm{~K}$ are shown in Table 2. The number of binding sites $n$ is approximately equal to 1 , indicating that there is one binding site in CAT for SPIONs binding during their interaction. The value of $K_{A}$ we obtained is on the order of $10^{4}$, indicating that SPIONs can interact with CAT easily.

\subsection{Identifications on the conformation changes of CAT}

\subsubsection{UV-vis spectroscopy}

UV-visible absorption spectra can be employed to explore the conformation change of CAT as shown in Fig. 3. The spectrogram contains two absorption peaks: one reflecting the framework conformation of CAT around $210 \mathrm{~nm}$ [27], and the other providing us with information of the aromatic amino acids around $280 \mathrm{~nm}$ [28]. It can be observed that the absorption peak at $210 \mathrm{~nm}$ decreases regularly with a conspicuously red-shift as the SPIONs concentration increases. These results indicated that SPIONs unfolded the skeleton structure of CAT. However the absorption peak at $280 \mathrm{~nm}$ was enhanced, which demonstrated that more aromatic acid residues were exposed to the aqueous environment.

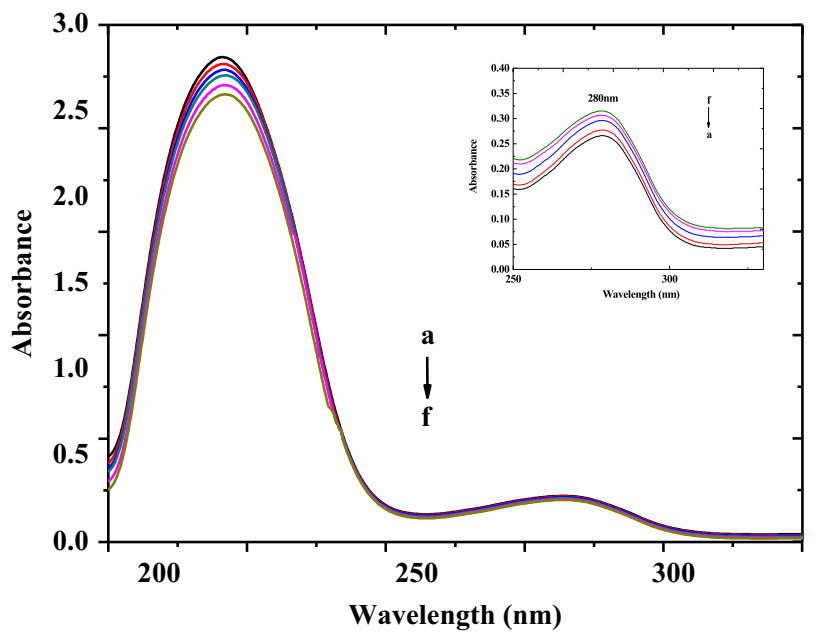

Fig. 3. UV-visible absorption spectra of CAT in the presence of SPIONs. Conditions: C (CAT) $1.0 \times 10^{-6} \mathrm{~mol} / \mathrm{L}$; SPIONs (a)-(f) $0 ; 2.5 ; 5.0 ; 7.5 ; 10.0 ; 12.5\left(\times 10^{-6} \mathrm{~mol} / \mathrm{L}\right)$; PBS $2.0 \times 10^{-2} \mathrm{~mol} / \mathrm{L}(\mathrm{pH}=7.40) ; T=293 \mathrm{~K}$.

In other words, the hydrophobicity of the microenvironment of CAT was decreased [29].

\subsubsection{Synchronous fluorescence spectroscopy}

To further demonstrate the interaction between CAT and SPIONs, synchronous fluorescence spectroscopy which can analyze the change of the molecular microenvironment in the vicinity of a chromophore was employed. When the $D$-value $(\Delta \lambda)$ between the excitation and emission wavelengths is set as 15 or $60 \mathrm{~nm}$, synchronous fluorescence of CAT gives the characteristic information of tyrosine or tryptophan residues [30], respectively.

The synchronous fluorescence spectra of CAT with various amounts of SPIONs are shown in Fig. 4. The maximum emission position of tyrosine residue (Fig. 4A) remained invariant, while a slight redshift (Fig. 4B, from $280 \mathrm{~nm}$ to $284 \mathrm{~nm}$ ) of maximum emission wavelength of tryptophan residue was observed with the increasing concentration of SPIONs. This phenomenon suggested that the microenvironment around the tryptophan residue of CAT was disturbed by SPIONs, and the tryptophan embedded in the nonpolar hydrophobic cavities were exposed to a more hydrophilic environment [31].

\subsubsection{Circular dichroism spectroscopy}

The $\mathrm{CD}$ measurement takes us nearer to understanding the possible influence of SPIONs binding on the secondary structure of CAT. It can be seen in Fig. 5 that the CD spectra of CAT exhibit two negative peaks in the UV region at 208 and $222 \mathrm{~nm}$, which are characteristic of the $\alpha$-helical structure of a protein.

The content of $\alpha$-helix was analyzed with the Jasco secondary structure manager software using the reference CD data Yang.jwr. (Table 3). When the molar ratio of CAT to SPIONs is $1: 25$, the $\alpha$ helix decreases from $32.4 \%$ to $29.1 \%$. $\alpha$-Helix is the important characteristic of secondary structure in CAT [32]. The decrease indicates that SPIONs bound to the amino acid residues of CAT loosen the protein skeleton, and change the conformation of protein. The results verified the conclusion obtained from absorption spectroscopy and synchronous fluorescence spectroscopy.

SPIONs in our experiment have a larger particle size compared with CAT. An $\alpha$-helix is taken as the example to investigate conformation changes in Fig. 6.

The water molecules of microenvironment were supplanted by a small amount of SPIONs. Normally, it is known that the water molecules can access only the amide moieties on the surface of 

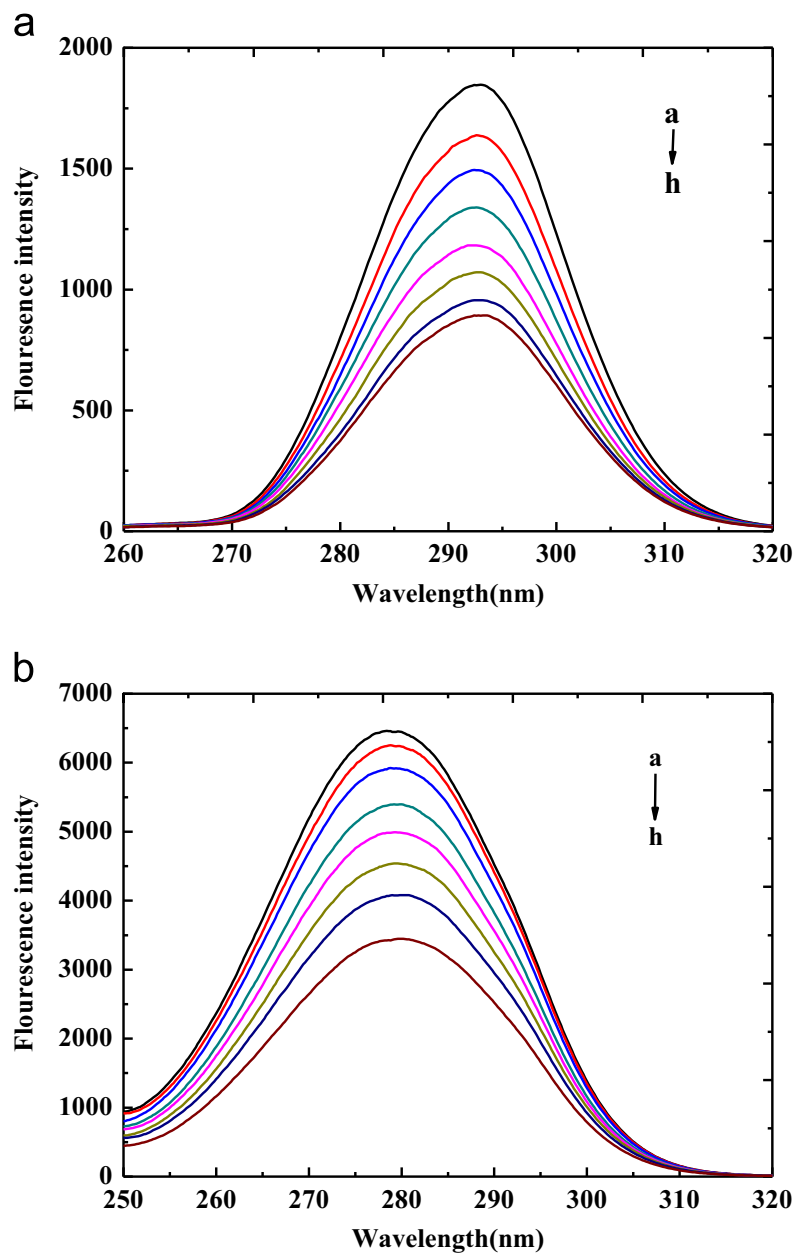

Fig. 4. Synchronous fluorescence spectra of CAT in the presence of SPIONs. (A) $\Delta \lambda=15 \mathrm{~nm}$, specific for Tyr. (B) $\Delta \lambda=60 \mathrm{~nm}$, specific for Trp. Conditions: $C(\mathrm{CAT})=$ $1.0 \times 10^{-6} \mathrm{~mol} / \mathrm{L}$; SPIONs (a)-(h) $0 ; 2.5 ; 5.0 ; 7.5 ; 10.0 ; 12.5 ; 15 ; 17.5\left(\times 10^{-6} \mathrm{~mol} / \mathrm{L}\right)$; PBS $2.0 \times 10^{-2} \mathrm{~mol} / \mathrm{L}(\mathrm{pH}=7.40) ; T=293 \mathrm{~K}$.

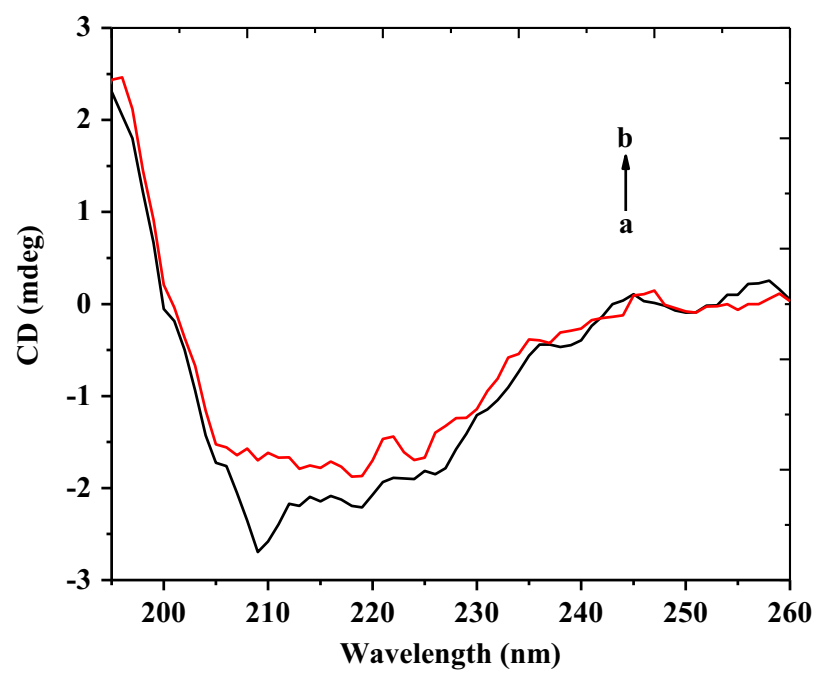

Fig. 5. CD Spectra of CAT in the presence of SPIONs. (a) CAT; (b) SPIONs and CAT. Conditions: $C$ (CAT) $1.0 \times 10^{-7} \mathrm{~mol} / \mathrm{L} ; \operatorname{SPIONs}(\mathrm{a}, \mathrm{b}): 0 ; 2.5\left(\times 10^{-6} \mathrm{~mol} / \mathrm{L}\right)$; $T=293 \mathrm{~K}$.

CAT. However, SPIONs have a significant denaturing impact on CAT with increasing concentration of SPIONs. We find that the amide moieties embedded in the hydrophobic pocket of the protein can
Table 3

The influence of SPIONs on the $\alpha$-helix content of CAT.

\begin{tabular}{lll}
\hline Lines in Fig.5 & $\begin{array}{l}\text { Molar ratio of CAT } \\
\text { to nanoFe } \mathbf{O}_{\mathbf{4}}\end{array}$ & $\boldsymbol{\alpha}$-Helix (\%) \\
\hline a & $1: 0$ & $32.4 \%$ \\
b & $1: 25$ & 29.1 \\
\hline
\end{tabular}

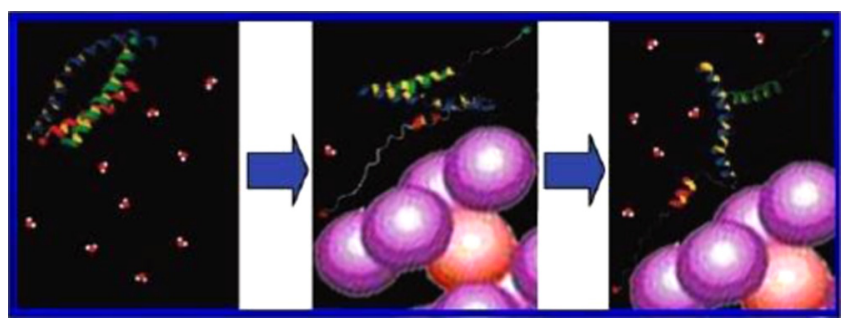

Fig. 6. Schematic diagram of the environmental change procedure, taking an $\alpha$ helix as an example.

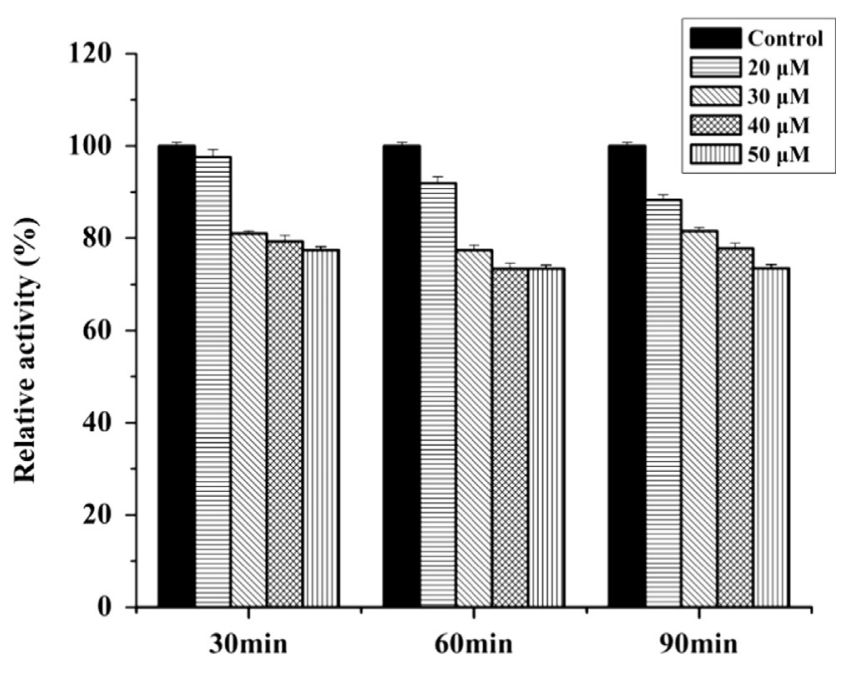

Fig. 7. Effect of exposure time and concentration of SPIONs on the activity of CAT. Conditions: $C(C A T)=1.0 \times 10^{-6} \mathrm{~mol} / \mathrm{L}$; PBS $2.0 \times 10^{-2} \mathrm{~mol} / \mathrm{L}(\mathrm{pH}=7.40) ; T=293 \mathrm{~K}$.

encounter water molecules that can be ascribed to the uncurled helical chain.

\subsection{CAT enzyme activity measurement}

The structural change of a protein is closely related to its biological function $[33,34]$. The above results indicate that CAT has undergone significant changes in structure and morphology after binding to SPIONs in vitro. The effects of different concentrations of SPIONs on the activity of CAT were investigated. As shown in Fig. 7, the CAT activity decreased with increasing SPIONs concentration ranging from 20 to $50 \mu \mathrm{M}$. The relative CAT activities decreased to $97.6 \pm 1.6 \%, 81.0 \pm 0.6 \%, 79.3 \pm 1.3 \%$ and $77.4 \pm 0.8 \%$ after treatment with $20,30,40$ and $50 \mu \mathrm{M}$ SPIONs for $30 \mathrm{~min}$, respectively.

The activity of CAT influenced by SPIONs was also investigated at different times. At a molar ratio of 20:1 (SPIONs to CAT), the activities of CAT were reduced to $91.9 \pm 1.4 \%$ for $60 \mathrm{~min}$ and $88.3 \pm 1.1 \%$ for $90 \mathrm{~min}$. Both SPIONs concentration and the reaction time of system have great effects on CAT activity. 


\section{Conclusions}

This work not only illuminates the mechanism of CAT interacting with SPIONs but also provides an approach for the evaluation of protein conformation and function. Based on our spectroscopic results, the SPIONs can loosen the skeleton of CAT and increase the exposure of amide moieties in the hydrophobic pocket. Besides, the conformational changes of CAT influenced the microenvironment of the activity site which resulted in the reduced CAT activity. In order to present an objective evaluation on the toxicity of nanophase materials, experimental studies on nanoparticles with biomolecules in vitro and in vivo (i.e. proteinSPIONs interactions) are being carried out in our laboratory and we are very optimistic on the prospects for the future.

\section{Acknowledgments}

This work is supported by National Natural Science Foundation of China (NSFC), China (20875055, 21277081), the Cultivation Fund of the Key Scientific and Technical Innovation Project, Research Fund for the Doctoral Program of Higher Education, Ministry of Education of the People's Republic of China, China (708058, 20130131110016) and Independent innovation program of Jinan (201202083) are also acknowledged.

\section{References}

[1] X. Zhao, R. Liu, Environ Int. 40 (2012) 244.

[2] V.S. Coker, N.D. Telling, G. van der Laan, R.A. Pattrick, C.I. Pearce, E. Arenholz F. Tuna, R.E. Winpenny, J.R. Lloyd, ACS nano 3 (2009) 1922.

[3] D.L. Huber, Small 1 (2005) 482.

[4] S.P. Foy, R.L. Manthe, S.T. Foy, S. Dimitrijevic, N. Krishnamurthy, V. Labhasetwar, ACS nano 4 (2010) 5217.
[5] A. Ito, M. Shinkai, H. Honda, T. Kobayashi, J. Biosci. Bioeng. 100 (2005) 1.

[6] J.W. Bulte, T. Douglas, B. Witwer, S.C. Zhang, E. Strable, B.K. Lewis, H. Zywicke, B. Miller, P. van Gelderen, B.M. Moskowitz, Nat. Biotechnol. 19 (2001) 1141.

[7] A.K. Gupta, M. Gupta, Biomaterials 26 (2005) 3995.

[8] N. Singh, G.J. Jenkins, R. Asadi, S.H. Doak, Nano Rev. 1 (2010).

[9] M. Mahmoudi, A. Simchi, A. Milani, P. Stroeve, J. Colloid Interface Sci. 336 (2009) 510.

[10] M. Mahmoudi, A. Simchi, M. Imani, J. Phys. Chem. C 113 (2009) 9573.

[11] H. Markides, M. Rotherham, A. El Haj, J. Nanomater.2012 (2012) 1.

[12] M.K. Yoo, I.Y. Park, I.Y. Kim, I.K. Park, J.-S. Kwon, H.J. Jeong, Y.Y. Jeong, C.S. Cho, J. Nanosci. Nanotechnol. 8 (2008) 5196.

[13] R.M. Cornell, Iron Oxides in the Laboratory Preparation and Characterization, 2nd edn., Wiley-VCH, Weinheim, Germany, 2000.

[14] S. Mohapatra, D. Pal, S.K. Ghosh, P. Pramanik, J. Nanosci. Nanotechnol. 7 (2007) 3193.

[15] P. Chelikani, I. Fita, P. Loewen, Cell. Mol. Life Sci. 61 (2004) 192.

[16] P. Montavon, K.R. Kukic, K. Bortlik, Anal. Biochem. 360 (2007) 207.

[17] M.F. Iannone, E.P. Rosales, M.D. Groppa, M.P. Benavides, Protoplasma 245 (2010) 15.

[18] B. Kalpakcioglu, K. Şenel, Clin. rheumatol. 27 (2008) 141.

[19] B.J. Day, Biochem. Pharmacol. 77 (2009) 285.

[20] Y. Jiang, J. Wong, Z. Pi, T. Ng, C. Wang, J. Hou, R. Chen, H. Niu, F. Liu, Environ. Toxicol. Pharmacol. 27 (2009) 396.

[21] G. Naik, K. Priyadarsini, J. Satav, M. Banavalikar, D. Sohoni, M. Biyani, H. Mohan, Phytochemistry 63 (2003) 97.

[22] R.L. Joseph, R. Lakowicz, Principles of Fluorescence Spectroscopy, Kluwer Academic/Plenum Publishers, New York, 1999.

[23] T. Yuan, A.M. Weljie, H.J. Vogel, Biochemistry 37 (1998) 3187.

[24] Y.Z. Zhang, B. Zhou, X.P. Zhang, P. Huang, C.H. Li, Y. Liu, J. Hazard. Mater. 163 (2009) 1345.

[25] J.R. Lakowicz, G. Weber, Biochemistry 12 (1973) 4161.

[26] W.R. Ware, J. Phys. Chem. 66 (1962) 455.

[27] D. Li, B. Ji, J. Jin, J. Lumin. 128 (2008) 1399.

[28] F. Wang, W. Huang, Z. Dai, J. Mol. Struct. 875 (2008) 509.

[29] Y. Wu, J. Pharm. Biomed. Anal. 44 (2007) 796.

[30] J. Zhu, X. Zhang, D. Li, J. Jin, J. Mol. Struct. 843 (2007) 38.

[31] Y.J. Hu, Y. Liu, Z.B. Pi, S.S. Qu, Bioorganic Med. Chem. 13 (2005) 6609

[32] N. Sreerama, R.W. Woody, Protein Sci. 13 (2004) 100.

[33] R. Lavery, S. Sacquin-Mora, J. biosci 32 (2007) 891.

[34] B.X. Huang, H.Y. Kim, C. Dass, J. Am. Soc. Mass. Spectrom 15 (2004) 1237. 